\title{
Phytocomponent p-hydroxycinnamic acid inhibits osteoclast-like cell formation in mouse bone marrow cultures
}

\author{
YING LING LAI and MASAYOSHI YAMAGUCHI \\ Laboratory of Endocrinology and Molecular Metabolism, Graduate School of Nutritional Sciences, \\ University of Shizuoka, 52-1 Yada, Suruga-ku, Shizuoka 422-8526, Japan
}

Received June 30, 2006; Accepted August 28, 2006

\begin{abstract}
The phytocomponent p-hydroxycinnamic acid (HCA) has been shown to have inhibitory effects on boneresorbing factor-stimulated bone resorption in rat femoral tissues in vitro. The effects of HCA on osteoclast-like cell formation in mouse bone marrow cultures in vitro were investigated. The bone marrow cells were cultured for 7 days in $\alpha$-minimal essential medium containing a bone-resorbing agent [parathyroid hormone (1-34)] $(\mathrm{PTH})$, prostaglandin $\mathrm{E}_{2}$ $\left(\mathrm{PGE}_{2}\right)$, or tumor necrosis factor- $\alpha(\mathrm{TNF}-\alpha)$ in effective concentrations. Osteoclast-like cell formation was estimated by staining for tartrate-resistant acid phosphatase, a marker enzyme of osteoclasts. The presence of PTH $\left(10^{-7} \mathrm{M}\right), \mathrm{PGE}_{2}$ $\left(10^{-5} \mathrm{M}\right)$, or TNF- $\alpha(10 \mathrm{ng} / \mathrm{ml})$ induced a remarkable increase in osteoclast-like multinucleated cells. These increases were significantly inhibited in the presence of HCA $\left(10^{-8}-10^{-5} \mathrm{M}\right)$. HCA $\left(10^{-6}\right.$ or $\left.10^{-5} \mathrm{M}\right)$ significantly inhibited osteoclast-like cell formation induced by dibutyryl cyclic adenosine monophosphate $\left(10^{-5} \mathrm{M}\right)$ or phorbol 12 -myristate 13 -acetate $\left(10^{-6} \mathrm{M}\right)$, an activator of protein kinase C. Also, HCA $\left(10^{-8}-10^{-5} \mathrm{M}\right)$ had a significant inhibitory effect on osteoclast-like cell formation induced by the receptor activator of NF-кB ligand (RANKL) $(10 \mathrm{ng} / \mathrm{ml})$ in the presence of macrophage colonystimulating factor (M-CSF) $(10 \mathrm{ng} / \mathrm{ml})$. The inhibitory effect of HCA $\left(10^{-6}\right.$ or $\left.10^{-5} \mathrm{M}\right)$ on RANKL plus M-CSF-induced osteoclast-like cell formation was not observed in the presence of cycloheximide $\left(10^{-7} \mathrm{M}\right)$, an inhibitor of protein synthesis in the transcriptional process, or 5,6-dichloro-1- $\beta$ D-ribofuranosylbenzimidazole $\left(10^{-6} \mathrm{M}\right)$, an inhibitor of transcription. This study demonstrates that HCA has a potent inhibitory effect on osteoclast-like cell formation in mouse bone marrow cultures. The inhibitory action of HCA may
\end{abstract}

Correspondence to: Dr Masayoshi Yamaguchi, Laboratory of Endocrinology and Molecular Metabolism, Graduate School of Nutritional Sciences, University of Shizuoka, 52-1 Yada, Surugaku, Shizuoka 422-8526, Japan

E-mail: yamaguch@u-shizuoka-ken.ac.jp

Key words: p-hydroxycinnamic acid, bone resorption, osteoclast, receptor activator of NF- $\mathrm{KB}$ ligand, bone marrow cell partly involve a newly synthesized protein component which is related to RANKL stimulation in osteoclastogenesis.

\section{Introduction}

Aging induces a decrease in bone mass $(1,2)$. Osteoporosis with its accompanying decrease in bone mass is widely recognized as a major public health problem. The most dramatic expression of the disease is represented by fractures of the proximal femurs $(3,4)$. Bone loss with aging may be due to decreased bone formation and increased bone resorption. Pharmacological and nutritional factors may prevent bone loss with aging $(5,6)$. Chemical compounds in food and plants that act on bone metabolism, however, are poorly understood.

Recent studies have shown that isoflavones $(7,8)$, which are contained in soybean, and menaquinone-7 $(9,10)$, an analogue of vitamin $\mathrm{K}_{2}$ which is essential for the $\gamma$-carboxylation of osteocalcin of bone matrix protein (11) and abundant in fermented soybean, have stimulatory effects on osteoblastic bone formation and inhibitory effects on osteoclastic bone resorption, thereby increasing bone mass. Of the various carotenoids (including ß-cryptoxanthin, lutein, lycopene, and $\beta$-carotene), which are present in fruit and vegetables, $\beta$-cryptoxanthin has been found to have unique anabolic effects on bone calcification $(12,13)$. B-Cryptoxanthin has stimulatory effects on osteoblastic bone formation (14) and inhibitory effects on osteoclastic bone resorption (15) in vitro. The supplementation of isoflavones, menaquinone-7 and $\beta$-cryptoxanthin has preventive effects on bone loss induced by ovariectomy in rats, which are an animal model of osteoporosis (16-18). Chemical factors in food and plants thus play a role in bone health and may be important in the prevention of bone loss with aging.

Cinnamic acid is present in many plants. p-Hydroxycinnamic acid is an intermediate-metabolic substance in plants, and is synthesized from thyrosine. Recently, it has been found that among cinnamic acid and other related compounds, p-hydroxycinnamic acid (HCA) has unique anabolic effects on bone components $(19,20)$. HCA has stimulatory effects on bone formation and inhibitory effects on bone resorption in rat femoral tissues in vitro (19). HCA may have a role in the prevention of osteoporosis with aging.

This study, moreover, was undertaken to determine whether HCA has inhibitory effects on osteoclastic cell formation. We found that HCA inhibits various bone- 
resorbing factor-induced osteoclast-like cell formation in mouse bone marrow cultures in vitro.

\section{Materials and methods}

Chemicals. $\alpha$-Minimal essential medium ( $\alpha$-MEM) and penicillin-streptomycin $(5000 \mathrm{U} / \mathrm{ml}$ penicillin, $5000 \mu \mathrm{g} / \mathrm{ml}$ streptomycin) were obtained from Gibco Laboratories. Fetal bovine serum was obtained from Bioproducts Inc. Synthetic human parathyroid hormone (1-34, PTH), prostaglandin $\mathrm{E}_{2}$ $\left(\mathrm{PGE}_{2}\right)$, tumor necrosis factor- $\alpha(\mathrm{TNF}-\alpha)$, receptor activator of NF- $\kappa \mathrm{B}$ ligand (RANKL, mouse), macrophage colonystimulating factor (M-CSF, mouse), phorbol 12-myristate 13acetate (PMA), dibutyryl cyclic adenosine monophosphate (DcAMP), cycloheximide, and 5,6-dichloro-1-B-D-ribofuranosylbenzimidazole (DRB) were obtained from Sigma Chemicals (St. Louis, MO, USA). p-Hydroxycinnamic acid (HCA), and other chemicals were obtained from Wako Pure Chemical Industries (Osaka, Japan). Chemicals were dissolved in distilled water or ethanol (99.5\%).

Animals. Male mice (ddY strain, 6 weeks old) were obtained from Japan SLC (Hamamatsu, Japan). The animals were fed commercial laboratory chow (solid) containing $1.1 \%$ phosphorus and $0.012 \%$ zinc, and were given distilled water. Mice were sacrificed by exsanguination.

Marrow cultures. Bone marrow cells were isolated from the mice, as reported elsewhere $(21,22)$. Briefly, bone ends of the femur were cut off, and the marrow cavity was flushed with $1 \mathrm{ml}$ of $\alpha$-MEM. The marrow cells were washed with $\alpha$-MEM and cultured in the same medium containing $10 \%$ heatinactivated fetal bovine serum with $1.0 \times 10^{7}$ cells $/ \mathrm{ml}$ in 24 well plates $(0.5 \mathrm{ml} /$ well $)$ in a water-saturated atmosphere containing $5 \% \mathrm{CO}_{2}$ and $95 \%$ air at $37^{\circ} \mathrm{C}$. The cells were cultured for 3 days, then $0.2 \mathrm{ml}$ of the old medium was replaced with fresh medium, and the cultured cells were maintained for an additional 4 days. Various concentrations of HCA were added to the culture medium containing either vehicle, PTH $\left(10^{-7} \mathrm{M}\right), \mathrm{PGE}_{2}\left(10^{-5} \mathrm{M}\right)$, or TNF- $\alpha(10 \mathrm{ng} / \mathrm{ml})$ in effective concentrations at the beginning of the cultures and at the time of medium change. In separate experiments, the respective media contained either vehicle, M-CSF (10 ng $/ \mathrm{ml})$ plus RANKL (10 ng/ml), PMA $\left(10^{-6} \mathrm{M}\right)$ or DcAMP $\left(10^{-5} \mathrm{M}\right)$. After being cultured for 7 days, cells adherent to the 24-well plates were stained for tartrate-resistant acid phosphatase (TRACP), a marker enzyme of osteoclasts $(23,24)$.

Enzyme histochemistry. Cultured cells adherent to the 24well plates were stained for TRACP. Briefly, cells were washed with Hanks' balanced salt solution and fixed with $10 \%$ neutralized formalin-phosphate ( $\mathrm{pH}$ 7.2) for $10 \mathrm{~min}$. After the culture dishes were dried, TRACP-staining was applied according to the method of Burstone (23). The fixed cells were incubated for $12 \mathrm{~min}$ at room temperature $\left(25^{\circ} \mathrm{C}\right)$ in an acetate buffer ( $\mathrm{pH}$ 5.0) containing both naphthol ASMX phosphate (Sigma) as a substrate and red violet LB salt (Sigma) as a stain for the reaction product in the presence of $10 \mathrm{mM}$ sodium tartrate (23). TRACP-positive multinucleated

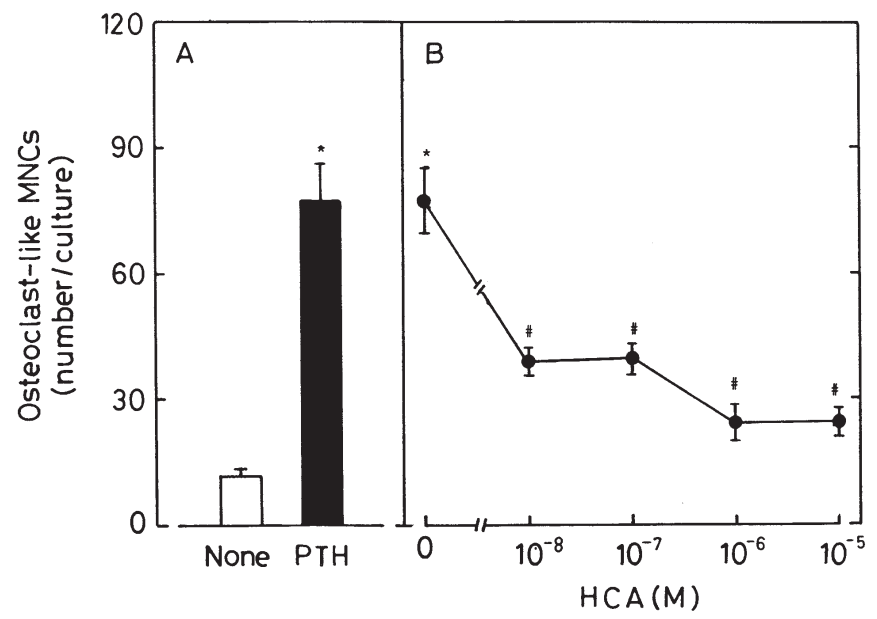

Figure 1. Effect of p-hydroxycinnamic acid (HCA) on PTH-induced osteoclast-like cell formation in mouse marrow cultures. Mouse marrow cells were cultured for 7 days in medium containing either vehicle, PTH $\left(10^{-7} \mathrm{M}\right)$, or PTH $\left(10^{-7} \mathrm{M}\right)$ plus HCA $\left(10^{-8}-10^{-5} \mathrm{M}\right)$. Cells were then fixed and stained for TRACP, and the number of TRACP-positive MNCs was scored. Each value is the mean \pm SEM of five cultures. ${ }^{*} \mathrm{p}<0.01$, compared with the control (none) value. ${ }^{\#} \mathrm{p}<0.01$ compared with the value of PTH alone. (A) White bar, none; black bar, PTH. (B) PTH plus HCA.

cells (MNCs) containing three or more nuclei were counted as osteoclast-like cells.

Statistical methods. Data were expressed as the mean \pm SEM. Statistical differences were analyzed using Student's paired t-test. We also used a multiple ANOVA to compare the treatment groups. A p value $<0.05$ was considered to indicate a statistically significant difference.

\section{Results}

Effects of p-hydroxycinnamic acid (HCA) on bone-resorbing factor-induced osteoclast-like cell formation in bone marrow cell cultures. The effect of HCA on bone-resorbing factorinduced osteoclast-like MNC formation in the mouse bone marrow culture system was examined (25-27). Mouse bone marrow cells were cultured for 7 days in medium containing either vehicle, PTH $\left(10^{-7} \mathrm{M}\right), \mathrm{PGE}_{2}\left(10^{-5} \mathrm{M}\right)$, or TNF- $\alpha(10 \mathrm{ng} /$ $\mathrm{ml})$ in the presence or absence of HCA $\left(10^{-8}-10^{-5} \mathrm{M}\right)$. The number of TRACP-positive MNCs was significantly increased in the presence of PTH (Fig. 1A), $\mathrm{PGE}_{2}$ (Fig. 2A), or TNF- $\alpha(10 \mathrm{ng} / \mathrm{ml})$ (Fig. 3A). TRACP-positive MNCs were not appreciably formed in the control culture without boneresorbing factors at any incubation time. The presence of HCA $\left(10^{-8}-10^{-5} \mathrm{M}\right)$ in the culture medium caused a significant decrease in the number of TRACP-positive MNCs stimulated by PTH (Fig. 1B), PGE $_{2}$ (Fig. 2B), or TNF- $\alpha$ (Fig. 3B). HCA in the range of $10^{-8}-10^{-5} \mathrm{M}$ did not have an inhibitory effect on the proliferation of bone marrow cells. This was independent of the presence of bone-resorbing factors (data not shown).

In another experiment, mouse bone marrow cells were cultured for 3 days in medium containing either vehicle, PTH $\left(10^{-7} \mathrm{M}\right)$, or $\mathrm{PGE}_{2}\left(10^{-5} \mathrm{M}\right)$. HCA $\left(10^{-6}\right.$ or $\left.10^{-5} \mathrm{M}\right)$ was added to the culture medium containing each bone-resorbing agent, and the cells were incubated for an additional 4 days. In this 


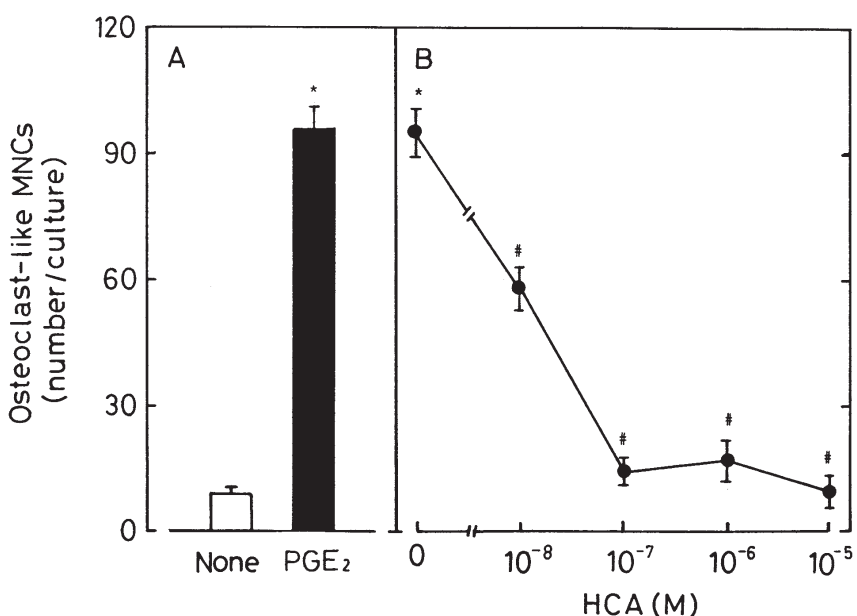

Figure 2. Effect of p-hydroxycinnamic acid (HCA) on $\mathrm{PGE}_{2}$-induced osteoclast-like cell formation in mouse marrow cultures. Mouse marrow cells were cultured for 7 days in medium containing either vehicle, $\mathrm{PGE}_{2}\left(10^{-5} \mathrm{M}\right)$, or $\mathrm{PGE}_{2}\left(10^{-5} \mathrm{M}\right)$ plus HCA $\left(10^{-8}-10^{-5} \mathrm{M}\right)$. Cells were then fixed and stained for TRACP, and the number of TRACP-positive MNCs was scored. Each value is the mean \pm SEM of five cultures. ${ }^{*} \mathrm{p}<0.01$ compared to the control (none) value. ${ }^{\#} \mathrm{p}<0.01$ compared to the value of $\mathrm{PGE}_{2}$ alone. (A) White bar, none; black bar, $\mathrm{PGE}_{2}$. (B) $\mathrm{PGE}_{2}$ plus $\mathrm{HCA}$.

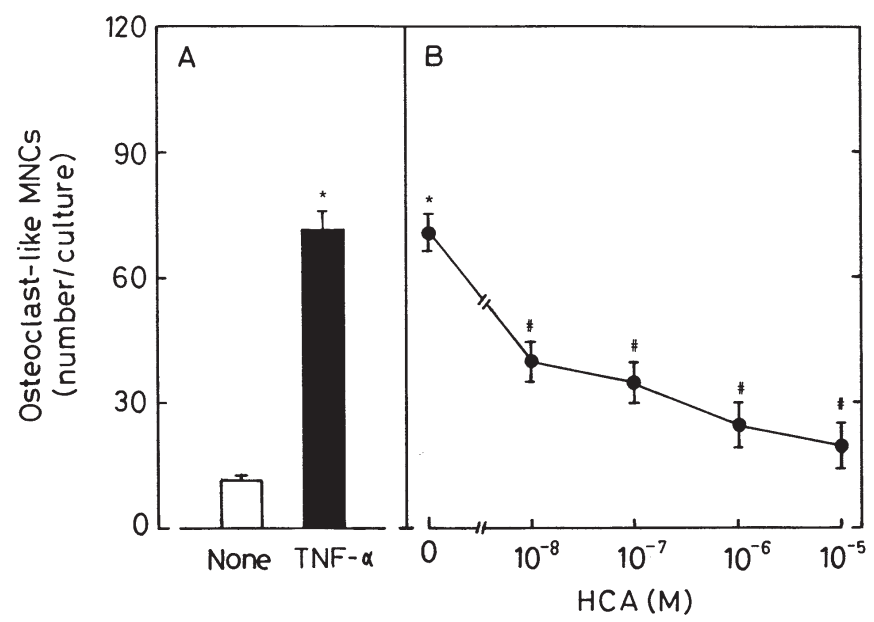

Figure 3. Effect of p-hydroxycinnamic acid (HCA) on TNF- $\alpha$-induced osteoclast-like cell formation in mouse marrow cultures. Mouse marrow cells were cultured for 7 days in medium containing either vehicle, TNF- $\alpha$ $(10 \mathrm{ng} / \mathrm{ml})$, or TNF- $\alpha(10 \mathrm{ng} / \mathrm{ml})$ plus HCA $\left(10^{-8}-10^{-5} \mathrm{M}\right)$. Cells were then fixed and stained for TRACP, and the number of TRACP-positive MNCs was scored. Each value is the mean \pm SEM of five cultures. ${ }^{*} \mathrm{p}<0.01$ compared to the control (none) value. ${ }^{\#} \mathrm{p}<0.01$ compared to the value of TNF- $\alpha$ alone. (A) White bar, none; black bar, TNF- $\alpha$. (B) TNF- $\alpha$ plus HCA.

case, the presence of HCA caused a significant inhibition of osteoclast-like MNC formation induced by bone-resorbing agents (Fig. 4).

Effects of HCA on intracellular signaling factor-induced osteoclast-like cell formation in bone marrow cell cultures. The effect of DcAMP or PMA on osteoclast-like MNC formation in mouse bone marrow culture was examined. The effect of PTH or $\mathrm{PGE}_{2}$ is mediated through cyclic AMP $(28,29)$. PMA is an activator of protein kinase $\mathrm{C}$, which is related to intracellular $\mathrm{Ca}^{2+}$ signaling (30). Mouse bone

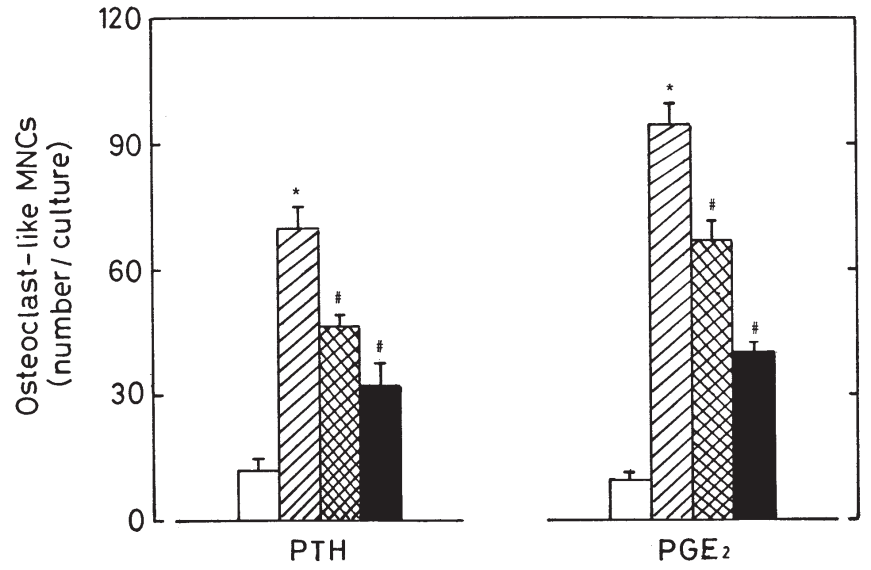

Figure 4. Effect of p-hydroxycinnamic acid (HCA) at the later stage of osteoclast-like cell formation in mouse marrow cultures. Mouse marrow cells were cultured for 7 days in medium containing either vehicle, PTH $\left(10^{-7} \mathrm{M}\right)$ or $\mathrm{PGE}_{2}\left(10^{-5} \mathrm{M}\right)$. After 3 days of culture, the medium was changed, HCA $\left(10^{-6}-10^{-5} \mathrm{M}\right)$ was added to the culture medium containing PTH $\left(10^{-7} \mathrm{M}\right)$ or $\mathrm{PGE}_{2}\left(10^{-5} \mathrm{M}\right)$, and the cells were cultured for an additional 4 days. Cells were then fixed and stained for TRACP, and the number of TRACP-positive MNCs was scored. Each value is the mean \pm SEM of five cultures. ${ }^{*} \mathrm{p}<0.01$ compared to the control (none) value. ${ }^{\#} \mathrm{p}<0.01$ compared to the value of PTH or $\mathrm{PGE}_{2}$ alone. White bars, control (none); hatched bars, $\mathrm{PTH}$ or $\mathrm{PGE}_{2}$; double-hatched bars, PTH or PGE 2 plus HCA $\left(10^{-6} \mathrm{M}\right)$; black bars, PTH or $\mathrm{PGE}_{2}$ plus $\mathrm{HCA}\left(10^{-5} \mathrm{M}\right)$.

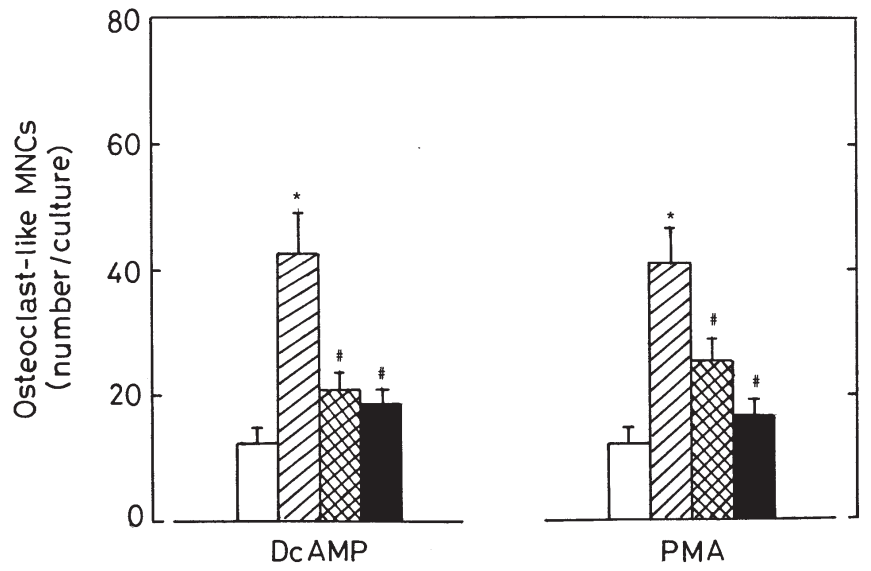

Figure 5. Effect of p-hydroxycinnamic acid (HCA) on DcAMP- or PMAinduced osteoclast-like cell formation in mouse marrow cultures. Mouse marrow cells were cultured for 7 days in medium containing either vehicle, $\operatorname{DcAMP}\left(10^{-5} \mathrm{M}\right)$, or PMA $\left(10^{-6} \mathrm{M}\right)$ in the presence or absence of HCA $\left(10^{-6}\right.$ or $\left.10^{-5} \mathrm{M}\right)$. Cells were then fixed and stained for TRACP, and the number of TRACP-positive MNCs was scored. Each value is the mean \pm SEM of five cultures. ${ }^{*} \mathrm{p}<0.01$ compared to the control (none) value. ${ }^{*} \mathrm{p}<0.01$ compared to the value of DcAMP or PMA alone. White bars, control (none); hatched bars, DcAMP or PMA; double-hatched bars, DcAMP or PMA plus HCA $\left(10^{-6} \mathrm{M}\right)$; black bars, DcAMP or PMA plus HCA $\left(10^{-5} \mathrm{M}\right)$.

marrow cells were cultured for 7 days in medium containing either vehicle, DcAMP $\left(10^{-5} \mathrm{M}\right)$, or PMA $\left(10^{-6} \mathrm{M}\right)$ in an effective concentration in the presence or absence of HCA $\left(10^{-6}\right.$ or $\left.10^{-5} \mathrm{M}\right)$. Osteoclast-like cell formation was significantly increased in the presence of DcAMP or PMA (Fig. 5). The effect of DcAMP or PMA was significantly inhibited by the addition of HCA $\left(10^{-6}\right.$ or $\left.10^{-5} \mathrm{M}\right)$ (Fig. 5). 


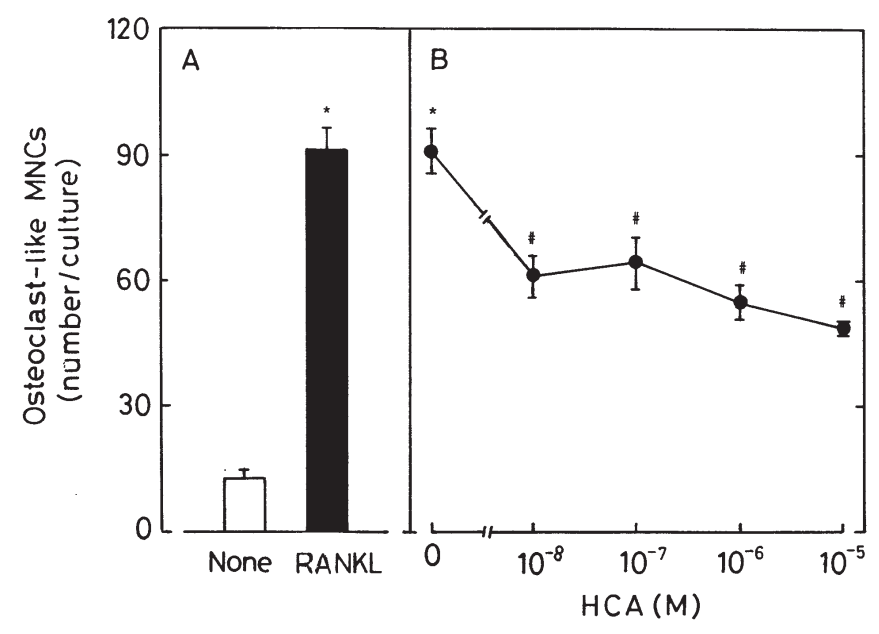

Figure 6. Effect of p-hydroxycinnamic acid (HCA) on M-CSF plus RANKL-induced osteoclast-like cell formation in mouse marrow cultures. Mouse marrow cells were cultured for 7 days in medium containing either vehicle, M-CSF $(10 \mathrm{ng} / \mathrm{ml})$ plus RANKL $(10 \mathrm{ng} / \mathrm{ml})$, or M-CSF $(10 \mathrm{ng} / \mathrm{ml})$ plus RANKL $(10 \mathrm{ng} / \mathrm{ml})$ in the presence of HCA $\left(10^{-8}\right.$ or $\left.10^{-5} \mathrm{M}\right)$. Cells were then fixed and stained for TRACP, and the number of TRACP-positive MNCs was scored. Each value is the mean \pm SEM of five cultures. ${ }^{*} \mathrm{p}<0.01$ compared to the control (none) value. ${ }^{*} \mathrm{p}<0.01$ compared to the value of M-CSF plus RANKL. (A) White bar, none; black bar, M-CSF plus RANKL. (B) M-CSF plus RANKL in the presence of HCA.

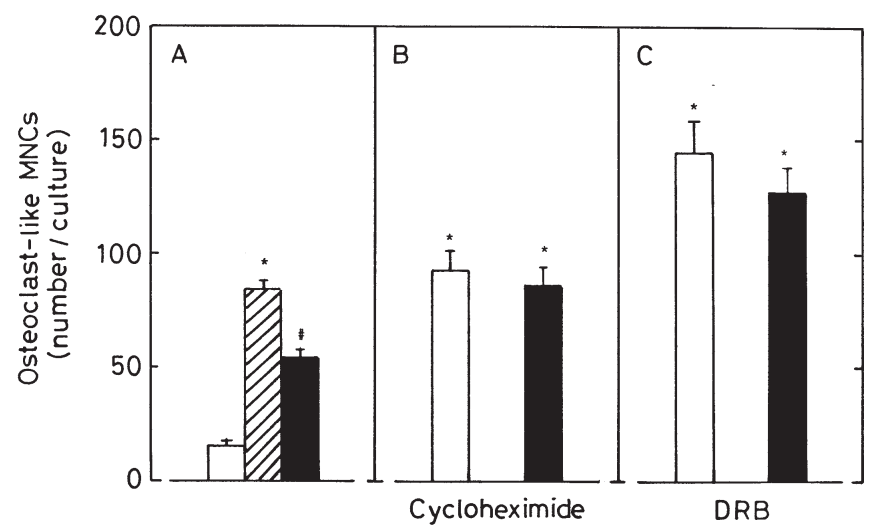

Figure 7. Effect of p-hydroxycinnamic acid (HCA) on M-CSF plus RANKL-induced osteoclast-like cell formation with or without the addition of cycloheximide or DRB in mouse marrow cultures. Mouse marrow cells were cultured for 7 days in medium containing either vehicle, M-CSF (10 ng $/ \mathrm{ml})$ plus RANKL $(10 \mathrm{ng} / \mathrm{ml})$ in the presence or absence of cycloheximide $\left(10^{-7} \mathrm{M}\right)$ or DRB $\left(10^{-6} \mathrm{M}\right)$ with or without HCA $\left(10^{-6} \mathrm{M}\right)$. Cells were then fixed and stained for TRACP, and the number of TRACP-positive MNCs was scored. Each value is the mean \pm SEM of five cultures. ${ }^{*} \mathrm{p}<0.01$ compared to the control (none) value. ${ }^{\#} \mathrm{p}<0.01$ compared to the value of RANKL plus M-CSF. (A) White bar, none; hatched bar, RANKL plus MCSF in the presence of HCA. (B) White bar, RANKL plus M-CSF with HCA in the presence of cycloheximide. (C) White bar, RANKL plus M-CSF in the presence of DRB; black bar, RANKL plus M-CSF with HCA in the presence of DRB

Effect of HCA on RANKL-induced osteoclast-like cell formation in bone marrow cell cultures. The effect of HCA on RANKL plus M-CSF-induced osteoclast-like MNC formation in mouse bone marrow culture was examined. RANKL and M-CSF are critical cytokines that stimulate osteoclast differentiation $(31,32)$. Mouse bone marrow cells were cultured for 7 days in medium containing either vehicle or RANKL plus M-CSF at $10 \mathrm{ng} / \mathrm{ml}$ of medium in the presence or absence of HCA $\left(10^{-8}-10^{-5} \mathrm{M}\right)$. The number of TRACP-positive MNCs was markedly increased in the presence of RANKL plus M-CSF (Fig. 6A). The presence of HCA $\left(10^{-8}-10^{-5} \mathrm{M}\right)$ in the culture medium caused a significant inhibition of osteoclast-like MNC formation induced by the cytokines (Fig. 6B).

The effect of HCA on RANKL plus M-CSF-induced osteoclast-like MNC formation in mouse bone marrow cultures was examined in the presence of cycloheximide, an inhibitor of the transcriptional process, and DRB, an inhibitor of transcription. To note, the presence of DRB $\left(10^{-6} \mathrm{M}\right)$ caused a significant increase in TRACP-positive MNC formation in the presence of RANKL plus M-CSF (10 ng/ml) (Fig. 7C). RANKL plus M-CSF-induced osteoclast MNC formation was also seen in the presence of cycloheximide $\left(10^{-7} \mathrm{M}\right)$ (Fig. 7B). The effect of HCA in inhibiting RANKL plus M-CSF-induced TRACP-positive HNC formation was not seen in the presence of cycloheximide or DRB (Fig. 7)

\section{Discussion}

The effects of cinnamic acid and other related phytocomponent compounds on bone metabolism have not yet been elucidated. More recently, we have found that p-hydroxycinnamic acid (HCA) stimulates bone formation and inhibits boneresorbing factor-induced bone resorption in vitro (19), and that the oral administration of HCA has anabolic effects on bone components in the femoral tissues of rats in vivo (20). This study, moreover, demonstrates that HCA has an inhibitory effect on various bone-resorbing factor-induced osteoclast-like cell formation in mouse bone marrow cultures in vitro. This finding supports the view that HCA inhibits osteoclastic bone resorption in vitro.

Culture with HCA caused a significant inhibition of PTH$\mathrm{PGE}_{2^{-}}$, or TNF- $\alpha$-induced osteoclast-like cell formation in mouse bone marrow cultured in vitro. HCA did not have an effect on the proliferation of bone marrow cells (data not shown), showing that HCA did not have a toxic effect on the cells. The inhibitory effect of HCA on osteoclast-like cell formation was observed to a greater extent at the earlier stage of osteoclast differentiation in bone marrow cultures. However, its inhibitory effect was also observed at the later stage of osteoclastogenesis. HCA has an effect on the process of differentiation from mononuclear osteoclast to osteoclast.

RANKL acts on osteoclast progenitors, and the cytokine stimulates osteoclast differentiation $(31,33)$. RANKL plays a pivotal role in osteoclast differentiation. RANKL expression is induced in osteoblastic factors, such as PTH, $\mathrm{PGE}_{2}$, and 1,25-dihydroxyvitamin $\mathrm{D}_{3}$, and the combined treatment of hematopoietic cells with M-CSF and the soluble form of RANKL (sRANKL) induced osteoclast differentiation in vitro (34). The receptor protein RANK is expressed on the surface of osteoclast progenitors (34). A soluble fragment containing part of the extracellular domain of RANKL (the carboxyterminal half of the protein, amino acids 158-316) is capable of promoting osteoclastogenesis in the presence of M-CSF. The supporting cells (osteoblasts or stromal cells) are not required for the activity (35). HCA significantly inhibited osteoclast-like cell formation induced by $\mathrm{PTH}$ or $\mathrm{PGE}_{2}$. 
Presumably, the inhibitory effect of HCA is partly involved in RANKL expression and/or RANKL action which are related to the effect of $\mathrm{PTH}$ or $\mathrm{PGE}_{2}$.

TNF- $\alpha$ is an autocrine factor in osteoclasts, promoting their differentiation, and mediating RANKL's induction of osteoclastogenesis (27). TNF- $\alpha$ has also been shown to mediate via its p55 receptor in lypoplosaccaride-stimulated osteoclastogenesis (36). TNF- $\alpha$-induced osteoclast-like cell formation in mouse bone marrow cultures was significantly inhibited by HCA. The inhibitory effect of HCA on TNF- $\alpha-$ stimulated osteoclastogenesis is probably the combination of effects by locally produced RANKL and TNF- $\alpha$.

The interaction of RANKL with its receptor RANK leads to the recruitment of the signaling adaptor molecules TRAFs (TNF receptor-associated factors) to the receptor complex and the activation of nuclear factor- $\kappa \mathrm{B}(\mathrm{NF}-\kappa \mathrm{B})$ and $\mathrm{c}-\mathrm{Jun}$ $\mathrm{N}$-terminal kinase (JNK) (37-40). The protein kinase C family enzyme has a role in the regulation of osteoclast formation and function potentially by participating in the extracellular signal-regulated kinase (ERK) signaling pathway of M-CSF and RANKL (41). PMA is an activator of protein kinase C (30). PMA significantly stimulated osteoclast-like cell formation in mouse bone marrow cultures, and the PMA-induced osteoclastogenesis was significantly inhibited by HCA. Moreover, HCA was found to have a significant inhibitory effect on DcAMP-induced osteoclast-like cell formation in mouse bone marrow cultures. Activation of the protein kinase $\mathrm{C}$ and protein kinase A pathways leads to increased RANKL effect, and HCA inhibits protein kinase $\mathrm{C}$ - or protein kinase A-related RANKL signaling in osteoclastogenesis. It is assumed that HCA has effects on preosteoclasts and/or osteoclasts.

Culture with HCA caused a significant inhibition of RANKL plus M-CSF-induced osteoclast-like cell formation in mouse bone marrow culture in vitro. This finding may support the view that HCA inhibits the binding of RANKL to receptor RANK, and that the compound suppresses RANKL signaling in osteoclastogenesis.

The effect of HCA in inhibiting RANKL plus M-CSFinduced osteoclast-like cell formation in mouse bone marrow cultures was completely blocked in the presence of cycloheximide, an inhibitor of protein synthesis in translational processes. The stimulatory effect of RANKL plus M-CSF on osteoclastogenesis was not inhibited in the presence of cycloheximide, an inhibitor of protein synthesis, or DRB, an inhibitor of transcriptional processes. The stimulatory effect of RANKL plus M-CSF on osteoclastogenesis was not inhibited in the presence of cycloheximide or DRB. To note, the effect of RANKL was significantly enhanced in the presence of DRB. It is speculated that RANKL stimulation on osteoclastogenesis induces a suppressor protein for osteoclastogenesis, which regulates osteoclast differentiation by an autocrine mechanism. Presumably, the inhibitory effect of HCA on osteoclastogenesis is partly involved in newly synthesized protein components which induce suppressor protein. Whether HCA has an effect on the expression of osteoprotegerin (OPG), a regulated suppressor of osteoclast differentiation $(31,33)$ in osteoblasts, is unknown, however.

The effect of HCA on the apoptosis of osteoclasts has not been clarified. If HCA has a stimulatory effect on the apoptosis of osteoclasts, the chemical may cause a decrease in the number of osteoclasts. This remains to be elucidated.

HCA is present in many plants. The physiological role of HCA has not been clarified. Recently, it has been shown that HCA has stimulatory effects on bone formation and inhibitory effects on bone resorption in rat femoral tissues in vitro (19), and that the oral administration of HCA has anabolic effects on bone components in the femoral tissues of normal rats (20). HCA may have a role in the prevention of bone loss with aging.

In conclusion, it has been demonstrated that the phytocomponent p-hydroxycinnamic acid (HCA) has an inhibitory effect on osteoclast-like cell formation induced by various factors in stimulating osteoclastogenesis in mouse bone marrow cultures in vitro. HCA may act as an inhibitor in RANKL stimulation which induces osteoclastogenesis.

\section{References}

1. Nishimoto SK, Chang C-H, Gendler E, Stryker WF and Nimni ME: The effect of aging on bone formation in rats: Biochemical and histological evidence for decreased bone formation capacity. Calcif Tissue Int 37: 617-624, 1985.

2. Schapia C, Slinn S, Sarid M, Mokadi S, Kabala A and Slibermann M: Calcium and vitamin D enriched diets increase and preserve vertebral mineral content in aging laboratory rats. Bone 16: 575-582, 1995.

3. Wild RA, Buchamain JR, Myers C and Demers LM: Declining adrenal androgen: an association with bone loss in aging women. Proc Soc Exp Biol Med 186: 335-360, 1987.

4. Cooper C and Melton J III: Epidemiology of osteoporosis. Trends Endocrinol Metab 3: 224-229, 1992.

5. Bonjour J-P, Schurch M-A and Rozzori R: Nutritional aspects of hip fractures. Bone 18: 1395-1445, 1996.

6. Yamaguchi M: Isoflavone and bone metabolism: Its cellular mechanism and preventive role in bone loss. J Health Sci 48: 209-222, 2002.

7. Sugimoto E and Yamaguchi M: Anabolic effect of genistein in osteoblastic MC3T3-E1 cells. Int J Mol Med 5: 515-520, 2000.

8. Yamaguchi M and Gao YH: Inhibitory effect of genistein on bone resorption in tissue culture. Biochem Pharmacol 55: 71-76, 1998.

9. Yamaguchi M, Sugimoto E and Hachiya S: Stimulatory effect of menaquinone-7 (vitamin $\mathrm{K}_{2}$ ) on osteoblastic bone resorption in rat bone tissue in vitro. Mol Cell Biochem 223: 131-137, 2001.

10. Yamaguchi $\mathrm{M}$ and $\mathrm{Ma} \mathrm{ZJ}$ : Inhibitory effect of menaquinone-7 (vitamin $\mathrm{K}_{2}$ ) on osteoclast-like cell formation and osteoclastic bone resorption in rat bone tissues in vitro. Mol Cell Biochem 228: 39-47, 2001.

11. Price PA: Vitamin K-dependent formation of bone gla protein (osteocalcin) and its function. Vitam Horm 42: 65-108, 1985.

12. Yamaguchi M and Uchiyama S: Effect of carotenoid on calcium content and alkaline phosphatase activity in rat tissues in vitro. The unique anabolic effect of $\beta$-cryptoxanthin. Biol Pharm Bull 26: 1188-1191, 2003.

13. Yamaguchi $M$ and Uchiyama S: B-Cryptoxanthin stimulates bone formation and inhibits bone resorption in tissue culture in vitro. Mol Cell Biochem 258: 137-144, 2004.

14. Uchiyama S and Yamaguchi M: B-Cryptoxanthin stimulates cell differentiation and mineralization on osteoblastic MC3T3-E1 cells. J Cell Biochem 95: 1224-1234, 2005.

15. Uchiyama $S$ and Yamaguchi $M$ : Inhibitory effect of $B$ cryptoxanthin on osteoclast-like cell formation in mouse marrow cultures. Biochem Pharmacol 67: 1297-1305, 2004.

16. Ma ZJ, Simanuki S, Igarashi A, Kawasaki Y and Yamaguchi M: Preventive effect of dietary fermented soybean on bone loss in ovariectomized rats; Enhancement with isoflavone and zinc supplementation. J Health Sci 46: 263-268, 2000.

17. Yamaguchi M, Kakuda H, Gao YH and Tsukamoto Y: Prolonged intake of femoral soybean (natto) diets containing vitamin $\mathrm{K}_{2}$ (menaquinone-7) prevents bone loss in ovariectomized rats. J Bone Miner Metab 18: 71-76, 2000

18. Uchiyama $S$ and Yamaguchi M: Oral administration of $\beta$ cryptoxanthin prevents bone loss in ovariectomized rats. Int $\mathbf{J}$ Mol Med 17: 15-20, 2006. 
19. Lai YL and Yamaguchi M: Phytocomponent p-hydroxycinnamic acid stimulates bone formation and inhibits bone resorption in rat femoral tissues in vitro. Mol Cell Biochem (In press).

20. Lai YL and Yamaguchi M: Oral administration of phytocomponent p-hydroxycinnamic acid has anabolic effects on bone calcification in femoral tissues of rats in vivo. J Health Sci 52: 308-312, 2006.

21. Takahashi N, Yamada H, Yoshiki S, Roodman GD, Mundy GR, Jones SJ, Boyde A and Suda T: Osteoclast-like cell formation and its regulation by osteotropic hormones in mouse bone marrow cultures. Endocrinology 122: 1373-1382, 1998.

22. Mundy GR and Roodman GD: Osteoclast ontogeny and function. In: Bone and Mineral Research. Peck WA (ed). Elsevier Science Publishers, Amsterdam, pp209-279, 1987.

23. Burstone MS: Histochemical demonstration of acid phosphatase with naphthol AS-phosphate. J Natl Cancer Inst 21: 523-539, 1958.

24. Minkin C: Bone acid phosphatase: tartrate-resistant acid phosphatase as a marker osteoclast function. Calcif Tissue Int 34: 285-290, 1992.

25. Klein-Nulend J, Fall PM and Raisz LG: Comparison of the effects of synthetic human parathyroid hormone (PTH)-(1-34)related peptide of malignancy and bovine PTH-(1-34) on bone formation and resorption in organ culture. Endocrinology 126: 223-227, 1990.

26. Klein DC and Raisz LG: Prostaglandins: stimulation of bone resorption of tissue culture. Endocrinology 86: 1430-1440, 1990.

27. Zou W, Hakim I, Tschoep K, Endres S and Bar-Shavit Z: Tumor necrosis factor- $\alpha$ mediates RANK ligand stimulation of osteoclast differentiation by an autocrine mechanism. J Cell Biochem 83: 70-83, 2001.

28. Sugimoto T, Kanatani M, Kaji H, Yamaguchi T, Fukase M and Chihara K: Second messenger signaling of PTH- and PTHRPstimulated osteoclast-like cell formation from hemopoietic blast cells. Am J Physiol 265: E367-E373, 1993.

29. Klein-Nulend J, Bowers PN and Raisz LG: Evidence that adenosine 3', 5'-monophosphate mediates hormonal stimulation of prostaglandin production in cultured mouse parietal bones. Endocrinology 126: 1070-1075, 1990.

30. Teti A, Colucci S, Grano M, Argentino L and Zallone AZ: Protein kinase $\mathrm{C}$ affects microfilaments, bone resorption, and $\left[\mathrm{Ca}^{2+}\right]$ sensing in cultured osteoclasts. Am J Physiol 263: C130-C139, 1992.

31. Zaidi M, Blair HC, Moonga BS, Abe E and Huang CL-H: Osteoclastogenesis, bone resorption, and osteoclast-based therapeutics. J Bone Miner Res 18: 599-609, 2003.
32. Hsu H, Lacey DL, Dunstan CR, Solovyev I, Colombero A, Timms E, Tan HL, Elliott G, Kelley MJ, Sarosi I, Wang L, Xia XZ, Elliott R, Chiu L, Black T, Scully S, Capparelli C, Morony S, Shimamoto G, Bass MB and Boyle WJ: Tumor necrosis factor receptor family member RANK mediates osteoclast differentiation and activation induced by osteoprotegerin ligand. Proc Natl Acad Sci USA 96: 3540-3545, 1999.

33. Tanaka S, Nakamura I, Inoue J-I, Oda $\mathrm{H}$ and Nakamura K: Signal transduction pathways regulating osteoclast differentiation and function. J Biol Miner Metab 21: 123-133, 2003.

34. Yasuda H, Shima N, Nakagawa N, Yamaguchi K, Kinosaki M, Mochizuki S, Tomoyasu A, Yano K, Goto M, Murakami A, Tsuda E, Morinaga T, Hagashino K, Udagawa N, Takahashi N and Suda T: Osteoclast differentiation factor is a ligand for osteoprotegerin/osteoclastogenesis-inhibitory factor and is identical to TRANCE/RANKL. Proc Natl Acad Sci USA 95: 3597-3602, 1998.

35. Burgess TL, Qian Y, Kaufman S, Ring BD, Van G, Capparelli C, Kelly M, Hsu H, Boyle WJ, Dunstan CR, Hu S and Lacey DL: The ligand for osteoprotegerin (OPGL) directly activates mature osteoclasts. J Cell Biol 45: 527-538, 1999.

36. Abu-Amer Y and Bar-Shavift Z: Regulation of TNF- $\alpha$ release from bone marrow-derived macrophages by vitamin D. J Cell Biochem 55: 435-444, 1994.

37. Anderson DM, Maraskovsky E, Billingsley WL, Dougall WC, Tometsko ME, Roux ER, Teepe MC, DuBose RF, Cosman D and Galibert L: A homologue of the TNF receptor and its ligand enhance T-cell growth and dendritic-cell function. Nature 390: 175-195, 1997.

38. Jimi E, Akiyama S, Tsurukai T, Okahashi N, Kobayashi K, Udagawa N, Nishihara T, Tahakashi N and Suda T: Osteoclast differentiation and function. J Immunol 163: 434-442, 1999.

39. Kim H-H, Kin H-M, Kwack K, Kim SW and Lee ZH: Osteoclast differentiation factor engages the PI 3-kinase, p38, and ERK pathways for avian osteoclast differentiation. J Biochem Mol Biol 34: 421-427, 2001.

40. Lee ZH, Kwack K, Kim KK, Lee SH and Kim H-H: Activation of c-Jun N-terminal kinase and activator protein 1 by receptor of NF-кB. Mol Pharmacol 58: 1536-1545, 2000.

41. Lee SW, Kwak HB, Chung WJ, Cheong H, Kim H-H and Lee ZH: Participation of protein kinase $C B \beta$ in osteoclast differentiation and function. Bone 32: 217-227, 2003. 